(59\%) provided written asthma plans for patients. Of these asthma plans $55(71 \%)$ recommend increasing inhaled steroids during a worsening. When using peak expiratory flow to guide the plan, $47 \%$ included advice on when to consult the GP and 51\% advice on when to seek emergency hospital treatment. The major barrier to writing plans was stated to be 'time' by 69 (53\%).

Discussion There is no NHS database of nurses doing asthma clinics. We contacted all practices and would be concerned that the $44 \%$ of non-respondents may have less enthusiasm for asthma care. Despite chronic disease management clinics being recommended for over 20 years over one third of nurses delivering asthma care have no formal asthma qualification and 31\% report they do not provide personal asthma plans. This is little different from year 2000 when $52 \%$ used plans. If asthma admission rates are to be reduced, ensuring staff are asthma trained and can enable patients to self-manage and control their lives, should be a quality standard.

\section{P90 SIMULATED BRONCHOSCOPY TRAINING DELIVERED BY EXPERIENCED PEERS IMPROVES CONFIDENCE OF NEW TRAINEES}

doi:10.1136/thx.2010.150979.41

${ }^{1} \mathrm{~A}$ R C Patel, ${ }^{2} \mathrm{~S}$ Mandal, ${ }^{1} \mathrm{~J} \mathrm{~J}$ P Goldring. ${ }^{1}$ Academic Unit of Respiratory Medicine, UCL Medical School, London, UK; ${ }^{2}$ Department of Respiratory Medicine, Colchester University Hospital, Essex, UK

Introduction and objectives Simulation training is widely employed by several medical and surgical specialties for inexperienced practitioners to acquire and consolidate practical skills. This approach is not routinely employed in respiratory medicine to train bronchoscopists. Survey data indicates a lack of confidence in performing bronchoscopy among new registrars. This study examined whether a 1-day simulated bronchoscopy course designed and delivered by experienced SpRs could improve this.

Methods Most of the 1-day course was divided in to three stations: 1. Hands-on use of two simulators (Accutouch, Immersion Corporation, USA), each trainee had at least 45 min of 1:1 tuition.

2. A slideshow of airway anatomy and pathology followed by MCQs addressing BTS guidelines.

3. Hands-on flexible bronchoscopy through a static bronchial tree model.

Trainees completed the Bronchoscopy Self-Assessment Tool (http://www.bronchoscopy.org), including an 8-item questionnaire (5-point Likert scale) measuring confidence at the beginning and end of the course. The questionnaire included identification of further training needs (I would like to learn more about: anatomy, abnormalities, technique, equipment, interpretation of findings).

Results 11 trainees (Male:Female, 8:3) attended the course, having performed a median of five bronchoscopies (interquartile range $5-30)$. Nine trainees had completed $<3$ months of StR training, two trainees had completed $<12$ months. Confidence scores were normally distributed, therefore are presented as mean \pm standard deviation. Confidence in all eight aspects improved, significantly in 7/8 (see Abstract P90 Table 1). Every trainee reported an overall increase in confidence (median 1.5 points on the 5 point scale, interquartile range $1.1-1.8, \mathrm{p}<0.001)$. Seven attendees identified fewer further training needs at the end of the course. Overall, trainees identified $36 \%$ fewer of the five further training choices they were given, indicating that these had been fully met.
Abstract P90 Table 1

\begin{tabular}{|c|c|c|c|c|}
\hline & $\begin{array}{l}\text { Pre-course } \\
\text { score } \\
\text { (mean } \pm \text { SD } \\
\text { out of } 5 \text { ) }\end{array}$ & $\begin{array}{l}\text { Post-course } \\
\text { score } \\
\text { (mean } \pm \text { SD } \\
\text { out of } 5 \text { ) }\end{array}$ & Difference & $\begin{array}{l}\text { Significance } \\
\text { (paired t-test) }\end{array}$ \\
\hline $\begin{array}{l}\text { Ability to identify } \\
\text { airway anatomy }\end{array}$ & $2.55 \pm 0.69$ & $3.40 \pm 0.70$ & $+18 \%$ & $p=0.004$ \\
\hline $\begin{array}{l}\text { Ability to identify } \\
\text { mucosal abnormalities }\end{array}$ & $2.27 \pm 0.79$ & $3.50 \pm 0.71$ & $+25 \%$ & $p=0.001$ \\
\hline $\begin{array}{l}\text { Ability to describe secretions } \\
\text { and other airway abnormalities }\end{array}$ & $2.55 \pm 0.82$ & $3.10 \pm 0.88$ & $+11 \%$ & $p=0.052$ \\
\hline $\begin{array}{l}\text { Ability to manoeuvre the } \\
\text { flexible bronchoscope }\end{array}$ & $2.64 \pm 1.03$ & $3.90 \pm 0.57$ & $+25 \%$ & $p=0.006$ \\
\hline $\begin{array}{l}\text { Ability to do a BAL through } \\
\text { the flexible scope }\end{array}$ & $2.30 \pm 0.82$ & $3.70 \pm 0.82$ & $+28 \%$ & $p<0.001$ \\
\hline $\begin{array}{l}\text { Ability to use a brush through } \\
\text { the flexible bronchoscope }\end{array}$ & $1.73 \pm 0.90$ & $3.50 \pm 0.53$ & $+35 \%$ & $\mathrm{p}<0.001$ \\
\hline $\begin{array}{l}\text { Ability to use biopsy } \\
\text { forceps through the scope }\end{array}$ & $1.64 \pm 0.81$ & $3.70 \pm 0.67$ & $+41 \%$ & $\mathrm{p}<0.001$ \\
\hline $\begin{array}{l}\text { I would now feel comfortable } \\
\text { performing this case in patient }\end{array}$ & $1.50 \pm 0.55$ & $3.56 \pm 0.88$ & $+41 \%$ & $\mathrm{p}=0.022$ \\
\hline
\end{tabular}

Conclusions A training course focusing on hands-on simulation run by experienced registrars for new registrars clearly increases confidence in technical aspects of performing bronchoscopy and interpreting findings. Although a proportion of training needs for most trainees appear to have been met by the course, it is not sufficient to meet them all. Early peer-to-peer simulated bronchoscopy training is a helpful addition to the current 'on-the-job' model.

\section{P91 CAN HEALTHCARE PROFESSIONALS IN A RESPIRATORY UNIT CORRECTLY SET AN OXYGEN FLOW RATE ON A STANDARD OXYLITRE MEDICAL REGULATOR?}

doi:10.1136/thx.2010.150979.42

S J Billington, C Mordaunt, R M Angus, L G Spencer. University Hospitals Aintree NHS Foundation Trust, Liverpool, England

Background It is known that prescribing practice in UK hospitals for oxygen is often suboptimal. In our Trust we are already working towards improving oxygen prescription practice. However, if we improve prescribing but do not ensure administration is also robust then patient safety will not be achieved. There is potential for serious harm and even death if oxygen management is incorrect (National Patient Safety Agency 2009/RRR006). We investigated how accurate our oxygen administration practice is.

Method Between January and March 2010 we randomly approached 100 healthcare professionals working on our respiratory wards. They were asked (1) to demonstrate where they would position the ball on a standard oxylitre medical regulator to set a flow rate of 21 of oxygen per minute, (2) whether they had received training in the use of oxygen flow metres and (3) if they had completed the Trusts self-assessment competency form for the use of oxygen flow metres.

Results Of the 100 staff approached 49 were nurses (various grades), 25 doctors (various grades), six physiotherapists, 19 nursing and one medical student. 65 staff set the flow rate correctly, with 33 setting it too high, that is, above the appropriate line and two too low, that is, below the line. 24 (24\%) staff had received either formal (medical or nursing school) or informal (from a colleague) training in the use of flow metres. Only seven of the staff had completed the Trusts self-assessment competency form; they all set the flow correctly.

Discussion The NPSA report 2009 identified a national problem regarding the inappropriate administration and management of 
oxygen. Our study indicates deficiencies in our practice in this specialist unit. There is a lack of clinical training and a low uptake of the self-assessment competency form. With these observations we are moving to make training and competency assessment mandatory for all clinical staff across the Trust. Also with the confusion we observed in correctly setting our hospitals traditional regulators we are considering switching to calibrated flow metres with a 'dial' to select flow which would reduce room for error and make oxygen administration safer.

\section{P92 TRAINING OPPORTUNITIES IN THORACIC ULTRASOUND FOR RESPIRATORY SPECIALIST TRAINEES IN THE WEST MIDLANDS DEANERY}

doi:10.1136/thx.2010.150979.43

T S Jordan, F Choudhary, R Heinink, S Mathew, I Hussain, M Allen. University Hospital of North Staffordshire NHS Trust, Stoke-on Trent, UK

Introduction The NPSA, ${ }^{1}$ supported by the BTS, ${ }^{2}$ recommends that chest drains for pleural effusions are placed using thoracic ultrasound (TUS). BTS pleural disease guidelines, currently under review, are likely to recommend the use of TUS. Royal College of Radiologists recommendations allow standardisation of TUS training, then assessment leading to Level-1 accreditation. ${ }^{3}$ The West Midlands Deanery, which comprises 13 Trusts providing 48 respiratory specialist training-posts, will require Level-1 competency in TUS as a CCT requirement. To achieve this there must be adequate training opportunities for trainees.

Methods and results We surveyed access to TUS training. Questionnaires were completed by 34 respiratory trainees from 11 Trusts (12 ST3, 9 ST4, 7 ST5, 1 ST6, 5 SpRs)-see Abstract P92 Table 1. Over half $(53 \%(18 / 34))$ were aware of Level-1 competency as a CCT requirement of which $33 \%(6 / 18)$ were unaware of criteria to achieve it. Most (91\% (31/34)) expressed concern about gaining sufficient TUS training for which responsibility was felt to be the Deanery's $(71 \%(24 / 34))$, the Trust $(26 \%(9 / 34))$ and the trainees's $(56 \%(19 / 34))$. Most had access to an US in their current Trust.

\section{Abstract P92 Table 1 Trainee responses}

\begin{tabular}{lr}
\hline & Number (\%) \\
\hline Number of TUS performed by trainees $(\mathrm{n}=34)$ & $16(47)$ \\
$1-20$ & $6(18)$ \\
$>20$ & $12(35)$ \\
None & \\
Training for those performing TUS ( $\mathrm{n}=22)$ & $11(50)$ \\
TUS course & $5(22)$ \\
TUS-competent supervisor only & $6(28)$ \\
Neither & \\
Not attended TUS course ( $\mathrm{n}=21)$ & $12(57)$ \\
Unable to get a place & $4(19)$ \\
Booked on course & $5(24)$ \\
Not tried & \\
Access to an US machine $(\mathrm{n}=34)$ & $11(32)$ \\
Yes-easily & $14(41)$ \\
Yes-with difficulty & $9(26)$ \\
No access & \\
\hline
\end{tabular}

Conclusion Much concern exists amongst respiratory trainees over TUS training and Level-1 accreditation. The majority (68\% (23/34) of trainees had not been on a TUS course mostly due to lack of availability, and were performing TUS without formal training; some of these without appropriate supervision. This clearly shows the need for greater access to recognised training opportunities in TUS. This may require local Trusts, in conjunction with the Deanery, to be more proactive in providing these opportunities and not rely on the availability of limited national courses.

\section{REFERENCES}

1. NPSA/2008/RRR003

2. British Thoracic Society Statement. BTS; Nov 2008.

3. Ultrasound Training Recommendations for Medical and Surgical Specialties. The Royal College of Radiologists 2005.

\section{P93 A SIMULATED BRONCHOSCOPY COURSE FOR NEW SPECIALIST TRAINEES}

doi:10.1136/thx.2010.150979.44

${ }^{1} \mathrm{~S}$ Mandal, ${ }^{2} \mathrm{~A}$ R C Patel, ${ }^{2} \mathrm{~J} \mathrm{~J}$ P Goldring. ${ }^{1}$ Department of Respiratory Medicine, Colchester University Hospital, Essex, UK; ${ }^{2}$ Academic Unit of Respiratory Medicine, UCL Medical School, London, UK

Introduction and objectives New trainees typically perform initial bronchoscopies on real patients under supervision. This model of training has safety and comfort implications relying on timely acquisition of skills, potentially compromised by a reduction in the number of bronchoscopies performed by trainees. Simulators have been validated in training novice practitioners. We present a model for initial bronchoscopy training by registrars for registrars.

Methods We developed a course based on survey data from NorthEast Thames trainees. We provided first year trainees with precourse material consisting of BTS guidelines and a presentation of bronchial anatomy. The day involved $1 \mathrm{~h}$ of theory, including indications, contra-indications, sedation, local anaesthesia, consent and management of complications. This was followed by a practical session with specialist nurses including assembling a bronchoscopy stack, troubleshooting and effective team-working. Most of the day was divided into three stations:

1. Use of two simulators (Accutouch, Immersion Corporation, USA), each trainee had $45 \mathrm{~min}$ of 1:1 tuition. Trainees were objectively scored using the validated Bronchoscopy Skills and Tasks Assessment Tool (Bronchoscopy International, USA). This score and freetext comments were sent to the trainees to discuss with consultants.

2. A slideshow of airway anatomy and pathology followed by MCQs addressing pre-course material.

3. Hands-on flexible bronchoscopy through a static bronchial tree model.

Feedback was assessed using a questionnaire at the end of the day Results $9 / 11$ trainees were within 3 months of starting StR training, 2/11 were within 12 months, having performed a median of five bronchoscopies (interquartile range 5-30). All trainees felt the course was pitched at the right level. They would all recommend this course to others, giving a rating of $4.8 / 5$. $90 \%$ thought the course should be carried out within the first 3 months of training. All participants would change their practice as a result of what had been learnt on the course. Suggestions for improvement included grey cases and even more hands-on simulation time.

Conclusions This potential model for bronchoscopy training was:

- Pitched at the right level.

- Delivered at an appropriate time.

- Received overwhelmingly positive feedback.

- Can be effectively delivered by experienced peers. 